\title{
Age, sex and residence: preferences of colonic polyps in Grodno population in the last three years
}

\begin{abstract}
The colonic polyp is the precursor of most carcinomas of the large intestine discovered in people who undergo colorectal screening or who have a diagnostic work-up for symptoms. Confirmatory evidence is derived from epidemiological, histological and clinical data demonstrating a close parallelism between polyps and cancer of the colon. Based on current knowledge, all colonic polyps should be removed to prevent the cancer development. Colorectal polyps are common, but there is a large geographical variation, so Belarus has the high incidences. In this study, we show the dynamics of the occurrence of patient's diagnosed with (D12) "Colonic polyp", as well as to study the individual characteristics of the manifestation of colonic polyps.
\end{abstract}

Keywords: colonic polyps, large intestine, colorectal cancer, surgery
Volume 7 Issue I - 2020

\author{
Salmin Roman,' Salmina Anastasiya, ${ }^{2}$ Rum \\ Tadevush, ${ }^{3}$ Valchkevich Dzmitry ${ }^{2}$ \\ 'Department of surgical diseases\#I, Grodno State Medica \\ University, Belarus \\ 2Department of Normal Anatomy, Grodno State Medical \\ University, Belarus \\ ${ }^{3}$ Department Surgery, Grodno University Clinic, Belarus
}

Correspondence: Valchkevich Dzmitry, Department of Normal Anatomy, Grodno State Medical University, Grodno, Belarus, Tel +3752978|4545, Email donn@tut.by

Received: December 12, 2019 | Published: January 14, 2020

\section{Introduction}

Management of the malignant colonic polyp remains a subject for debate even after almost two decades of experience. ${ }^{1,2}$ Some researchers believe all patients should have a colonic resection; others argue that only certain cases call for laparotomy, while still others hold for a selective approach but with varying criteria. ${ }^{3-6}$ Colorectal cancer is one of the most common oncological diseases, and over the last 5 years, the individual risk of developing this pathology has increased and reached on about $6 \% .{ }^{7}$ Patients older than 55 years form the main risk group for this disease. However, there is a significant trend of "rejuvenation" of the disease, which often can occur in young people. The proportion of patients aged 40 to 50 years has increased and reached $10 \%{ }^{7,8}$

Hereditary forms of colorectal cancer occur in about 5\%, the established hereditary predisposition reaches $30 \%$. The external causes are the main etiological factors in $65 \%$ of cases., ${ }^{2,8}$ The accumulation of mutations in the epithelial cells of the colon precedes appearance of a malignant tumor in most of cases. Morphologically, it is manifested by a benign tumor called a polyp, which clinically is free of symptoms. ${ }^{8,9}$

Thus, the following is characteristic of colorectal cancer: 1) an increase in its spread in people aged 40-50;2) unknown environmental factors are the main mutagen; 3) asymptomatic clinical course of precancerous colon disease. All the above-mentioned features do not contribute to the early diagnosis and treatment of the disease at the stage of a benign tumor. ${ }^{2,9,10}$

The aim of the research is to study the dynamics of the occurrence of patients diagnosed with (D12) "Colonic polyp", as well as to study the individual characteristics of the manifestation of colonic polyps.

\section{Materials and methods}

The object of the study was 742 patients diagnosed with a colonic polyp who underwent treatment at the Grodno University Hospital from 2017 to 2019. The statistical studies were carried out with the help of PC soft "Statistica 13". Multivariate analysis of variance was used to assess the reliability of the differences.

\section{Results and discussion}

In 2017, the quantity of patients hospitalized in Grodno University Hospital is 759 people, 205 from them (27\%) were diagnosed with a colonic polyp. In 2018, the quantity of hospitalized patients increased slightly, and amounted to 805 people, 245 of which (30\%) were diagnosed with a colonic polyp, what is statistically significantly $(p<0.05)$ more than in 2017. In 2019, the volume of hospitalized patients decreased slightly and amounted to 795 people, 292 from them $(37 \%)$ were diagnosed with a colonic polyp, what is statistically significantly $(\mathrm{p}<0.05)$ more than in 2017 and 2018.

Among the patients diagnosed with a colonic polyp in 2017, $56 \%$ (115 individuals) were female and 44\% (90 individuals) were male. In 2018, 53\% (130 individuals) and 47\% (115 individuals) correspondingly, however, it is not significant different with those in 2017. In 2019, the percentage of female was 58 (169 individuals) and male-42 (123 individuals), while the proportion of women became significantly larger comparing $2018(\mathrm{p}<0.05)$.

In 2017 , patients with a diagnosis of colonic polyp were divided on rural residents (29\%) and urban residents (71\%). In 2018, the amount of the rural population with colonic polyps was $25 \%$, and that of the urban population was $75 \%$, what did not significantly differ comparing 2017. In 2019, the amount of the rural residents with colonic polyps decreased and amounted to $21 \%$, while the urban population was in $79 \%$, what significantly $(\mathrm{p}<0.05)$ differ from the same indicators for 2017 and 2018. The percentage of age dynamics of the manifestation of colonic polyp is shown in the Table 1. According to the above table, the percentage of patients who are in between 40-60 ages suffering from polyps of the colon has been increased in three years $(p<0.05)$. 
Table I The percentage of age dynamics of the manifestation of colonic polyp

\begin{tabular}{|c|c|c|c|c|c|c|c|c|c|c|c|c|}
\hline $\begin{array}{l}\text { The age of } \\
\text { patients }\end{array}$ & $30-40$ & & $40-50$ & & $50-60$ & & $60-70$ & & Older tha & & Total & \\
\hline Year of study & Absolute & $\%$ & Absolute & $\%$ & Absolute & $\%$ & Absolute & $\%$ & Absolute & $\%$ & Absolute & $\%$ \\
\hline 2017 & 7 & 3.2 & 15 & 7.3 & 70 & 34.2 & 96 & 47.1 & 17 & 8.2 & 205 & 100 \\
\hline 2018 & 8 & 3.4 & 29 & 11.7 & 114 & 46.6 & 83 & 33.7 & 11 & 4.6 & 245 & 100 \\
\hline 2019 & 4 & 1.4 & 49 & 16.8 & 130 & 44.6 & 101 & 34.6 & 8 & 2.6 & 292 & 100 \\
\hline
\end{tabular}

\section{Conclusion}

During the period from 2017 to 2019, an increase in the frequency of hospitalization of patients diagnosed with a colonic polyp was recorded. The proportion of female is higher than male among patients diagnosed with a polyp of the colon throughout last three years. There is a tendency to increase this indicator. The proportion of urban residents is significantly higher than rural ones among patients with a colonic polyp; this indicator tends to increase also. The proportion of patients in the age of 40-50 years is continuously increasing among the patients diagnosed with a colonic polyp.

\section{Acknowledgments}

None.

\section{Conflicts of interest}

The authors declare there are conflicts of interest.

\section{References}

1. Hofstad B, Andersen SN, Nesbakken A. Colorectal polyps. Tidsskr Nor Laegeforen. 2007;127(20):2692-2695.

2. Kit OI. Hereditary colorectal cancer: genetics and screening. Ros Journal Gastroenterol Hepatol Coloproctol. 2018;28(3):18-25.
3. Jin Y, Yao L, Zhou P. Risk analysis of the canceration of colorectal large polyps. Zhonghua Wei Chang Wai Ke Za Zhi. 2018;21(10):1161-1166.

4. Seitz U, Bohnacker S, Seewald S, et al. Is endoscopic polypectomy an adequate therapy for malignant colorectal adenomas? Presentation of 114 patients and review of the literature. Dis Colon Rectum. 2004;47(11):1789-1796.

5. Cohen LB, Waye JD. Treatment of colonic polyps - practical considerations. Clin Gastroenterol. 1986;15(2):359-376.

6. Winawer SJ, Zauber AG, Fletcher RH, et al. Guidelines for colonoscopy surveillance after polypectomy: a consensus update by the US MultiSociety Task Force on Colorectal Cancer and the American Cancer Society. Gastroenterology. 2006;130(6):1872-1885.

7. Odintsova IN. Epidemiology of colorectal cancer. Siberian Oncology Journal. 2017;16(4):89-95.

8. Pasevich DM, Sushkov SA, Semenov VM. Molecular genetic aspects of malignant neoplasms of the colon. News of surgery. 2016;24(2):184 192.

9. Wang M, Lu JJ, Kong WJ, et al. Clinical characteristics of sentinel polyps and their correlation with proximal colon cancer: A retrospective observational study. World J Clin Cases. 2019;7(20):3217-3225.

10. Wolff WL, Shinya H, Cwern M, et al. Cancerous colonic polyps. "Hands on" or "hands off?". Am Surg. 1990;56(3):148-152. 